\title{
PERSPEKTIF POLITICAL JUSTICE DI DALAM IMPLEMENTASI BPJS PBI DI KOTA SURABAYA
}

\author{
Tamy Nur Nabilah ${ }^{1}$, Kris Nugroho ${ }^{2}$ \\ ${ }^{I}$ Departemen Ilmu Politik, Fakultas Ilmu Sosial dan Ilmu Politik, Universitas Airlangga. \\ tamynurnabb@gmail.com \\ ${ }^{2}$ Departemen Ilmu Politik, Fakultas Ilmu Sosial dan Ilmu Politik, Universitas Airlangga. \\ kris.nugroho@fisip.unair.ac.id
}

\begin{abstract}
This study discusses the perspective of Political Justice in the Implementation of BPJS PBI in Surabaya. The study aims to determine the implementation of BPJS PBI in Surabaya has fulfilled Political Justice and the implementation of BPJS PBI in Surabaya is adequate as a form of political justice. The research method that uses is descriptive qualitative because it presents a detailed description of the situation or social phenomenon. Methods of data collection using direct interviews with resource persons, including Head of Surabaya City Health Office, Surabaya City DPRD Commission D, Lurah, PBJS recipient community. The results showed that the implementation of BPJS PBI in Surabaya City had not yet fulfilled Political Justice, based on indicators of fairness, equality, equality, and impartiality. The implementation of BPJS PBI in the city of Surabaya is also inadequate as a form of political justice because the state still determines justice in terms of profit and loss to health because the way of thinking lies in the amount of current contributions that do not match the actual calculation. Therefore, the implementation of the Health Insurance for the Poor program funded by the Surabaya City Regional Budget has not yet fulfilled the concept of Political Justice. This can be seen that there are still Health Insurance recipients who are not on target because of lack of accuracy in the process of verifying data on the poor in Surabaya, easy to get a Poor Certificate (SKM) that applies only once, and there are still groups of welfare recipients, so there is no meet the aspects of equity and justice.
\end{abstract}

Keywords: Political justice, politics of health, implementation policy.

\section{PENDAHULUAN}

Negara sesuai amanat UUD 1945 pada asas dasarnya dibentuk untuk memberikan kesejahteraan dan rasa keadilan bagi rakyatnya (welfare state) (Cahyandari et al., 2015). Salah satu konsep welfare state yang diamanatkan oleh UUD 1945 dapat dilihat pasal 28H ayat (1) dan (3) bahwa setiap orang berhak hidup sejahtera, bertempat tinggal, mendapatkan lingkungan hidup yang baik dan sehat, memperoleh pelayanan kesehatan, dan jaminan sosial. Untuk melakukan hal tersebut, Pasal 34 ayat (2) UUD 1945 menyatakan bahwa negara harus mengembangkan sistem jaminan sosial (Putri, 2014).

Salah satu program di Indonesia untuk menghadirkan prinsip kesejahteraan sosial dan perwujudan jaminan sosial adalah melalui Badan Penyelenggara Jaminan Sosial (BPJS). Menurut UU Nomor 24 Tahun 2011 Tentang Badan Penyelenggara Jaminan Sosial (BPJS), selanjutnya disebut UU BPJS, BPJS merupakan badan hukum dengan tujuan yaitu mewujudkan terselenggaranya pemberian jaminan untuk terpenuhinya kebutuhan dasar hidup yang layak bagi setiap peserta dan/atau anggota keluarganya.

Salah satu jenis BPJS adalah BPJS Kesehatan yang dibentuk sebagai perlindungan sosial untuk menjamin kesehatan masyarakat terjamin dan terpenuhinya kebutuhan dasar hidup yang lebih baik dan layak (Vyandri, 2016). Dasar asas yang digunakan oleh BPJS dalam menyelenggarakan sistem jaminan 
kesehatan nasional merupakan sistem yang berpedoman pada asas kemanusiaan, dengan manfaat keadilan sosial bagi seluruh rakyat Indonesia (BPJS Kesehatan, 2018).

Faktanya, seperti yang dikutip dalam Cahyandari et al. (2016), dalam pengimplementasian terlihat BPJS kesehatan belum siap menjalankan tugas dan wewenangnya sehingga menimbulkan ketidakpastian dan kebingungan bagi semua pihak terkait dan terdapat pemaksaan oleh negara untuk seluruh rakyat sebagai peserta BPJS dalam implementasi BPJS kesehatan.

Menurut Basuki, et al. (2016), aktor kebijakan sebagai faktor penting keberhasilan suatu kebijakan. Aktor penting pelaksanaan program kebijakan JKN adalah pemerintah sebagai instrumen langsung dari negara. Pemerintah idealnya berupaya memberikan keadilan politik (political justice) yang dapat memenuhi kebutuhan kesehatan sebagai salah satu kebutuhan dasar masyarakat. Hasil penelitian Salim \& Dartanto (2013) mengungkapkan bahwa program PBI bagi masyarakat kurang mampu perlu keterlibatan pengawasan ketat oleh aktor kebijakan karena dinilai kurang sejalan dengan prinsip gotong royong (iuran). Hal ini karena masih ada celah bagi yang mampu turut serta dalam kepesertaan program PBI.

Teori keadilan yang dirumuskan John Rawls mengatakan bahwa setiap orang memiliki hak yang sama terhadap kebebasan asasi. Ini seharusnya menjadi prinsip bagi institusi-institusi sosial bila ingin mewujudkan keadilan sosial (Anggara, 2013). William Godwin melalui teori political justice memberikan kritik radikal terhadap institusi pemerintah yang tidak adil. Dengan kata lain, keadilan harus bertujuan menghasilkan pemerataan dan kesetaraan, serta ketidakberpihakan (Godwin, 1793). Oleh karena itu, keadilan politik sebagai barometer untuk menimbang semua persoalan moral, masalah tingkah laku yang baik maupun buruk. Keadilan politik merupakan keadilan yang murni, mendetail dan netral, tidak timpang karena kepentingan kelompok atau pun kelas-kelas. Keadilan politik dikenal secara konseptual adalah memiliki makna dasar "sama". Dengan demikian, Keadilan politik mengandung arti memelihara hak-hak individu dan memberi hak-hak kepada setiap orang yang berhak menerimanya. Sebaliknya, ketidakadilan politik adalah kesewenang-wenangan suatu Lembaga Negara yang diselewengkan oleh para aktor politik yang berdampak pada masyarakat luas (Fisk, 1989).

Keadilan politik dalam penelitian ini mengacu pengertian keadilan yang diutarakan John Rawls mengenai keadilan itu fairness bahwa setiap orang memiliki hak yang sama terhadap kebebasan asasi dan Godwin menyatakan keadilan harus bertujuan menghasilkan pemerataan dan kesetaraan, serta ketidakberpihakan.

Penelitian ini memanfaatkan metode kualitatif deskriptif dengan meneliti permasalahan yang tengah terjadi di masyarakat yang kemudian dijelaskan secara detail sesuai dengan hasil temuan data yang telah diperoleh. Fokus dari penelitian ini Implementasi BPJS PBI di Kota Surabaya dalam Perspektif Political Justice. Data yang didapatkan melalui hasil wawancara mendalam yang telah dikelompokkan dan dianalisis agar dapat menjawab pertanyaan penelitian. Data yang diperoleh kemudian diinterpretasikan dengan teori-teori yang telah dijelaskan sebelumnya. Dengan demikian, penelitian ini dapat menjelaskan secara detail mengenai implementasi BPJS PBI di Kota Surabaya 
apakah sudah memenuhi Political Justice dan implementasi BPJS PBI di Kota Surabaya apakah sudah memadai sebagai bentuk political justice.

Dalam lingkup di Surabaya, hasil pengamatan ditemukan bahwa implementasi kebijakan BPJS Kesehatan anggota PBI di Surabaya menunjukkan sosialisasi masih lemah terutama pada awal implementasi karena sering terjadi penolakan dan adanya ketidaktahuan. Tetapi dorongan untuk menkover masyarakat miskin dengan jaminan kesehatan telah berjalan dengan baik, sehingga penerapan model implementasi kebijakan dalam program BPJS Kesehatan untuk PBI di Surabaya perlu ditambahkan faktor lingkungan politik, sosial, dan ekonomi masyarakat.

Dengan gambaran tersebut menunjukkan bahwa peran pemerintah yang optimal diharapkan memberikan dampak pada aktor pelaksana lainnya seperti lembaga BPJS Kesehatan, rumah sakit, pihak swasta, dan masyarakat sendiri. Oleh karena itu, penelitian ini ingin mengkaji peran negara dalam menghantarkan BPJS sebagai bagian dari kebijakan politik yang berdimensi keadilan di bidang kesehatan. Sebagaimana diamanatkan dalam UUD 1945, BPJS sebagai bagian dari proyek keadilan sosial di bidang kesehatan dilaksanakan oleh pemerintah kota dalam hal ini kota Surabaya. Berbagai masalah dan kendala BPJS akan dikaji melalui temuan data terutama terkait kontribusi pemerintah kota Surabaya dalam mewujudkan keadilan politik (political justice). Dengan melihat BPJS dari perspektif political justice, dapat menambah pengetahuan kita akan makna dari sebuah kebijakan itu harus adil dan berdampak luas. Selain itu juga peneliti berharap perspektif political justice ini membuat kita mengetahui seperti apa keadilan pada program yang salah satunya sangat dibanggakan oleh Walikota Surabaya.

\section{Implementasi BPJS PBI di Kota Surabaya Belum Memenuhi Political Justice}

Political justice merupakan konsep keadilan politik yang diperoleh setiap warga negara. Politik hubungannya dengan keadilan, memiliki keterikatan antara satu sama lainnya. Keseimbangan dalam politik bisa tercipta jika keadilan menjadi roh dalam setiap kebijakan politik. Indikator untuk mengukur political justice mengacu pada teori keadilan yang diutarakan John Rawls dan Godwin yaitu prinsip fairness, pemerataan, kesetaraan, dan ketidakberpihakan.

Secara prinsip konteks fairness, implementasi BPJS PBI Kota Surabaya belum memberikan rasa keadilan bagi warga Surabaya. Terbukti masih banyak warga yang diduga telah sejahtera menerima BPJS PBI. Secara prinsip pemerataan juga masih belum merata dari baik dari segi pelayanan, pendistribusian, maupun penetapan tarif, hal ini disebabkan minimnya rumah sakit yang bekerja sama dengan BPJS yang tidak berimbang dengan jumlah peserta PBI, fee dokter yang tidak lancar membuat penanganan menjadi terhambat, dan lain-lain. Secara prinsip kesetaraan dinilai implementasi BPJS PBI Kota Surabaya masih belum memenuhi prinsip tersebut karena masih ada ketidakseimbangan pembagian penerima bantuan iuran (PBI). Secara ketidakberpihakan juga implementasi BPJS PBI Kota Surabaya masih dinilai syarat keberpihakan, hal ini terjadi pada perlakukan pelayanan penanganan pasien berdasarkan kelas. Dari data lapangan dan analisis dapat disimpulkan bahwa implementasi BPJS PBI di Kota Surabaya belum memenuhi political justice. John Rawls dalam konsep keadilan seperti 
menggunakan mind game. Adalah rasional misalnya, bagi seorang yang kaya-raya untuk menentang usulan menaikkan pajak untuk kesejahteraan umum. Namun demikian sebaliknya, untuk seorang yang miskin, adalah rasional bagi dirinya mendukung usulan menaikkan pajak untuk kesejahteraan umum. Keduanya memiliki kepentingan yang berbeda dan akan berpendapat sesuai dengan kepentingannya masing-masing. Pertanyaannya, kebijakan manakah yang akan diambil oleh pemerintah? Kebijakan manakah yang paling adil? Sebagai jawaban atas pertanyaan seperti ini, Rawls menyuguhkan jawaban dengan menggunakan dua kondisi imajiner yang menghasilkan satu rule; Original Position, Veil of Ignorance dan Maximin Rule (Anggara, 2013).

Original Position atau posisi awal adalah sebuah kondisi imajiner di mana setiap orang berada dalam keadaan awal yang sifatnya setara. Diasumsikan bahwa dalam keadaan awal ini semua orang memiliki hak dan akses yang sama untuk memilih prinsip yang akan diterapkan apabila dikembalikan kepada kenyataan nantinya. Original Position ini berguna dalam membuat kebijakan publik, atau misalnya konstitusi. Dalam membuat konstitusi hams diumpamakan bahwa masyarakat pada saat konstitusi itu belum dibuat, berada dalam keadaan in natura, dalam kondisi setara, tanpa kelas dan tanpa hierarki. Dalam pandangan ini dari segi BPJS PBI, pemerintah kota Surabaya khususnya melihat kebutuhan kesehatan sebagai kebutuhan yang harus disokong oleh pemerintah kota, maka dari itu dana APBD untuk kesehatan alokasinya sangat besar. Orang-orang yang berada dalam Original Position ini kemudian diasumsikan berada di belakang veil of ignorance. Dalam hal pembuatan konstitusi misalnya, diasumsikan tidak tahu, bahwa setelah dikembalikan kepada kenyataan akan menjadi turunan ningrat, orang berkulit putih, anggota suku terpencil, industrialis kaya, buruh atau orang kulit hitam. Mereka tidak tahu tingkat intelektualitas mereka nantinya, kekuatan, kesehatan dan hal-hal sejenisnya. Karena, apabila mereka tahu bagaimana nantinya status dan peranan mereka dalam kehidupan kemasyarakatan, maka dalam membuat klausul konstitusi mereka akan cenderung berpihak pada kepentingannya. Yang nantinya menjadi industrialis ingin agar upah buruh murah, yang nantinya ditakdirkan menjadi buruh ingin gaji yang paling tinggi dan banyak libur. Dengan Veil of ignorance, masyarakat tidak tahu posisi mereka dalam kenyataan. Veil of ignorance ini penting supaya konstitusi, hukum atau kebijakan publik lainnya yang dihasilkan nantinya berlaku adil bagi setiap anggota masyarakat karena mereka semua dalam Original Position memiliki kesetaraan dan tidak bisa melihat kepada kenyataan karena dihalangi oleh Veil of Ignorance maka pengambilan keputusan yang paling rasional bagi para pihak adalah keputusan Maximin (Maximum Minimorum), mengambil keputusan yang paling maksimal dari pilihan minimal. Rawls membatasi keadilan sebagai "fairness", dengan mengemukakan bahwa pemerintah bertanggung jawab untuk memelihara anggota masyarakat yang kurang beruntung (Anggara, 2013). Merefleksikan dari pendapat Rawls, sisi BPJS PBI ini memelihara masyarakat yang kurang beruntung namun sisi kesetaraan dalam implementasi ini tidak ada, karena di kota Surabaya sendiri adanya beberapa kelompok masyarakat yang menerima BPJS PBI secara cuma-cuma tanpa perlu daftar. 


\section{Implementasi BPJS PBI di Kota Surabaya Belum Memadai Sebagai Bentuk Political Justice}

"Ora Trimo dibantu ta piye, aku iki ditolak mlebu IGD soale ra gowo rujukan, nah keadaan panik opo isok mbak sek sempet jauk rujukan, yo pada akhire aku ditolong ambek dokter kono tapi staff'e sik eling aku kata-katae" (Mutmainah)

Berdasarkan temuan diketahui bahwa pelaksanaan program Jaminan Kesehatan Bagi Masyarakat Miskin yang dibiayai APBD Kota Surabaya belum memadai sebagai bentuk Political Justice. Hal ini terlihat bahwa penerima Jaminan Kesehatan masih ada yang tidak tepat sasaran karena kurang ketelitian proses verifikasi data warga miskin di Kota Surabaya. Selain itu, mudahnya mendapat Surat Keterangan Miskin (SKM) yang berlaku hanya satu kali pakai atau menurut perwali selama satu bulan tanpa ada tindak lanjut pendataan atau integrasi Data Kemiskinan antara Bappemas dengan kelurahan di Kota Surabaya. Hal ini tidak berkaitan isi kebijakan namun terletak pada pelaksanaan kebijakan. Implementasi program PBI BPJS belum memenuhi political justice juga akibat masih adanya pengelompokan golongan penerima kesejahteraan, sehingga tidak memenuhi aspek pemerataan dan keadilan. Contohnya saja dapat kita lihat di salah satu Perwali yakni Perwali nomor 61 tahun 2015. Yang di mana Perwali itu mengatur dan memutuskan beberapa pihak kelompok masyarakat yang terjamin langsung dari peraturan itu mendapatkan BPJS PBI. Kelompok masyarakatnya di antara lainnya yakni : Kelompok Bunda Paud, Kelompok Kader KB, Kelompok Kader Jentik dan sebagainya. Dan dari penelitian yang saya lakukan, rerata masyarakat yang tergabung ke kelompok masyarakat tersebut adalah masyarakat golongan ibu-ibu yang di mana ekonominya berkecukupan. Di sini saya melihat sisi masyarakat yang kurang mampu di mana dirinya sendiri jika untuk mendaftar dipersulit maupun untuk gabung pada kelompok masyarakat juga tidak memiliki aksesnya pun.

Menurut Plato yang dikutip dalam Nasution (2014:120) munculnya negara karena adanya hubungan timbal balik dan saling membutuhkan antara sesama manusia. Plato juga mengatakan bahwa negara ideal menganut prinsip mementingkan kebajikan (virtue). Begitu pentingnya prinsip kebajikan, hingga Plato beranggapan bahwa negara yang terbaik bagi manusia adalah negara yang penuh dengan kebajikan (keadilan) di dalamnya. Teori keadilan menurut Plato menekankan pada harmoni atau keselarasan. Bagi Plato keadilan tidak dihubungkan secara langsung dengan hukum. Baginya keadilan dan tata hukum merupakan substansi umum dari suatu masyarakat yang membuat dan menjaga kesatuannya. Konsepsi keadilan Plato yang demikian ini dirumuskan dalam ungkapan "giving each man his due" yaitu memberikan kepada setiap orang apa yang menjadi haknya. Untuk itu, hukum perlu ditegakkan dan Undang-undang perlu dibuat.

Di sisi lain Gostin menggunakan istilah keadilan substantif dalam hal pemenuhan kesehatan. Menurut Gostin, keadilan substantif dalam masalah kesehatan berkenaan dengan "the just distribution of health benefit and burdens". Maksudnya penerapan konsep keadilan substantif adalah bahwa para individu di hadapan yang lainnya berhak atas kedudukan relatif berupa kesetaraan atau ketidaksetaraan tertentu. Ini merupakan sesuatu yang harus dipertimbangkan dalam ketidakpastian kehidupan sosial 
ketika beban atau manfaat hendak didistribusikan. Ini juga merupakan sesuatu yang harus dipulihkan ketika terganggu. Dari situ menurut tradisi keadilan dipandang sebagai pemeliharaan atau pemulihan keseimbangan atau jatah bagian (Kurnia, 2013).

Berdasarkan konstruksi konsep keadilan Aristoteles keadilan distributif merupakan tugas dari pemerintah kepada warganya untuk menentukan apa yang dapat dituntut oleh warga negara dalam negaranya. Konstruksi keadilan yang demikian ini membebankan kewajiban bagi pembentuk Undangundang untuk memperhatikannya dalam merumuskan konsep keadilan ke dalam suatu Undang-undang (Kurnia, 2013).

Secara teoretis konsep keadilan Plato berdasar pada aliran filsafat idealisme, sedangkan konsep keadilan Aristoteles bertolak dari aliran filsafat realisme. Filsafat Plato mendasarkan diri pada alam ide yang bersifat mutlak dan abadi. Landasan filsafatnya ialah percaya dan menerima sepenuhnya alam nyata sebagai objektivitas. Sebaliknya Aristoteles menekankan filsafatnya pada kesadaran, maksudnya dalam pandangan Aristoteles titik sentralnya adalah kesadaran yang ada pada subyek yang berpikir (Nasution, 2014:121-122). Berdasarkan hal ini bagi kaum liberal keadilan dipahami sebagai suatu ketertiban rasional yang di dalamnya hukum alamiah ditaati dan sifat dasar manusia diwujudkan. Berbeda dengan kaum liberal, penganut utilitarianisme menolak digunakannya ide hukum alam dan suara akal dalam teorinya. Konsep keadilan pada aliran ini didasarkan pada asas kemanfaatan dan kepentingan manusia.

Konsep keadilan pada jaman modern diwarnai dengan berkembangnya pemikiran-pemikiran tentang kebebasan. Aliran ini mendasarkan diri pada nilai-nilai dalam ajaran etika dari mazhab Stoa khususnya individualisme, sanksi moral dan penggunaan akal. Dalam bidang politik dianut konsepsi tentang pemerintahan demokrasi yang dapat menjamin tercapainya kebebasan. Tradisi liberalisme sangat menekankan kemerdekaan individu. Istilah liberalisme erat kaitannya dengan kebebasan, titik tolak pada kebebasan merupakan garis utama dalam semua pemikiran liberal (Nasution, 2014:122). Bagi penentang utilitrian, keadilan menolak argumen yang menyatakan bahwa hilangnya kebebasan sebagian orang dapat dibenarkan atas asas manfaat yang lebih besar yang dinikmati oleh orang-orang lain. Oleh karena itu dalam suatu masyarakat yang adil, kebebasan warganegara yang sederajat tetap tidak berubah, hakhak yang dijamin oleh keadilan tidak tunduk pada tawar-menawar politik ataupun pada pertimbangan kepentingan sosial (Nasution, 2014:120). Maka dari itu disisi ini program BPJS PBI yang terpusat ini diharapkan juga dicontoh dan diperluas di daerah lain seperti halnya kota Surabaya. Karena kesehatan itu sendiri juga pada dasarnya sebagai aspek dasar dalam hidup yang berkeadilan.

Berdasarkan sekian banyak pengertian dan teori-teori yang dikemukakan para ahli, pada umumnya menyangkut mengenai hak dan kebebasan, peluang dan kekuasaan pendapat dan kemakmuran. Berbagai definisi keadilan di atas menunjukkan bahwa dalam kehidupan bermasyarakat dan bernegara, apa yang menjadi kepentingan bersama, akan mudah dicapai apabila masyarakat ditata menurut cita-cita keadilan. Keadilan menuntut agar semua orang diperlakukan sama, jadi keadilan merupakan suatu nilai yang mewujudkan keseimbangan antara bagian-bagian dalam masyarakat, antara 
tujuan pribadi dan tujuan bersama. Dalam kaitannya implementasi BPJS PBI Kesehatan Kota Surabaya, keadilan harus berprinsip adil, bersifat hukum, sah menurut hukum, tidak memihak, sama hak, layak, wajar secara moral dan benar secara moral sehingga dapat mencerminkan rasa keadilan bagi warganya. Dengan demikian, peran aktor sangat sentral dalam keberhasilan implementasi BPJS PBI, baik dalam perumusan, pelaksanaan, maupun evaluasi kebijakan.

\section{SIMPULAN}

Implementasi BPJS PBI di Kota Surabaya belum memenuhi Political Justice. Hal ini terlihat dari beberapa indikator Political Justice meliputi fairness: belum memberikan rasa keadilan; pemerataan: masih belum merata dari baik dari segi pelayanan, pendistribusian, maupun penetapan tarif; kesetaraan: masih belum setara dalam pendistribusian peserta PBI; dan ketidakberpihakan: masih tebang pilih dalam penanganan peserta PBI sesuai kelasnya. Peran aktor kebijakan dalam hal ini pemerintah sudah sepatutnya menjadi kekuatan yang harus menegakkan hukum untuk keadilan melalui kebijakan yang dibuat dan mekanisme implementasi kebijakan.

Anggaran juga menjadi persoalan penting dalam pelaksanaan suatu kebijakan serta disposisi kebijakan. Dukungan dan kemauan yang kuat dari pihak pelaksana kebijakan dapat memperlancar implementasi kebijakan. Seperti dukungan pihak kelurahan yang profesional. Namun masalah pemerataan penerima BPJS PBI masih belum optimal serta pelayanan mungkin kurang, seperti susah mencari fasilitas kesehatan yang $24 \mathrm{jam}$. Persoalan rujukan, juga masih terlalu rumit. Sementara peserta PBI mendapatkan hak yang sama untuk bisa berobat ketika sedang sakit. Perbedaannya hanya pada kamar perawatannya saja. Peserta PBI masuk ke dalam golongan kelas 3 dengan ruang perawatan paling bawah, sedangkan untuk obat dan pertanggungan sama.

Pelaksanaan program Jaminan Kesehatan Bagi Masyarakat Miskin yang dibiayai APBD Kota Surabaya terlihat belum memenuhi konsep Political Justice. Pertama, penerima Jaminan Kesehatan masih ada yang tidak tepat sasaran karena kurang ketelitian proses verifikasi data warga miskin di Kota Surabaya. Kedua, masih mudahnya mendapat Surat Keterangan Miskin (SKM) yang berlaku hanya satu kali. Ketiga, masih adanya pengelompokan golongan penerima kesejahteraan, sehingga tidak memenuhi aspek pemerataan dan keadilan.

Keseimbangan dalam politik bisa tercipta jika keadilan menjadi roh dalam setiap kebijakan politik. Merujuk pada masalah keadilan, political justice merupakan sistem diasosiasikan dengan kebajikan. Negara seharusnya berdiri di atas segala kelompok dan golongan dengan bersikap adil dan tidak memihak secara politik. Tidak seharusnya negara yang diwakili pemerintah bekerja hanya untuk kelompok tertentu dan menyingkirkan kelompok lain yang berseberangan pandangan politik dengan cara-cara ketidakadilan dengan menggunakan atau memperalat infrastruktur negara seperti lembagalembaga negara yang seharusnya hanya bekerja untuk negara, mengabdi kepada negara dan hanya melakukan kepentingan negara. Negara yang diwakili oleh pemerintah sudah sepatutnya menjadi kekuatan yang harus menegakkan hukum untuk keadilan, bukan justru menyiasati political justice demi 
kepentingan kelompok tertentu. Political justice peran sentral dalam kehidupan berbangsa dan bernegara. Maka keadilan politik sebagai barometer untuk menimbang semua persoalan moral, masalah tingkah laku yang baik maupun buruk. Political justice merupakan keadilan yang murni, mendetail dan netral, tidak timpang karena kepentingan kelompok atau pun kelas-kelas.

Political justice seharusnya menjadi alat perlindungan negara untuk memberikan keadilan dan kemakmuran bagi rakyatnya. Faktanya, Implementasi BPJS PBI belum memadai sebagai bentuk Political Justice. Hal ini karena ketidakadilan masih tersebar tidak merata di ruang nasional. Di sejumlah provinsi masyarakat umum masih miskin atau kurang merata, sementara di provinsi-provinsi lainnya pembangunan telah cukup merata, meskipun demikian juga provinsi-provinsi lainnya telah menyaksikan suatu perkembangan ketidakadilan yang cepat. Dengan kata lain, penjumlahan tingkat ketidakadilan secara nasional telah gagal menangkap pola-pola geografis dari ketidakadilan yang relevan secara politik.

\section{DAFTAR PUSTAKA}

Anggara, S (2013) Teori keadilan John Rawls kritik terhadap demokrasi liberal. Jispo, 1(1), 1- 11. https://doi.org/10.15575/jispo.v1i1.710

Basuki EW, Sulistyowati RN, \& Herawati (2016) Implementasi kebijakan jaminan kesehatan nasional oleh BPJS Kesehatan di Kota Semarang, 1-11.

BPJS Kesehatan (2018) Sejarah Perjalanan Jaminan Sosial di Indonesia. Diakses 10 Juni 2019, dari https://bpjs-kesehatan.go.id/bpjs/pages/detail/2013/4

Cahyandari D, Istislam, \& Hamidi J (2015) Hak monopoli negara dalam penyelenggaraan jaminan sosial perspektif negara kesejahteraan. Jurnal Hukum, 1-26.

Fisk M (1989) The State and Justice: An essay in political theory. Radical Philosophy Review of Books. USA: Cambridge University Press. https://doi.org/10.5840/radphilrevbooks199132

Godwin W (1793) An Enquiry Concerning Political Justice, Vol I, I(Book I), 1-323.

Kurnia TS (2013) Hak atas Derajat Kesehatan Optimal Sebagai HAM di Indonesia. Bandung: PT. Alumni.

Nasution BJ (2014) Kajian Filosofis tentang Konsep Keadilan dari Pemikiran Klasik sampai Pemikiran Modern, Yustisia, Vol. 3 No.2 Mei - Agustus 2014.

Putri AE (2014) Paham SJSN: Sistem Jaminan Sosial Nasional. Jakarta: Dewan Jaminan Sosial Nasional (DJSN).

Salim Z \& Dartanto T (2013) Menggapai kesejahteraan bersama melalui sjsn: bisakah dengan payung robek? Kajian Kebijakan The Habibie Center, (June).

Vyandri, M. A. (2016). Implementasi kebijakan BPJS Kesehatan di Kota Surabaya. Jurnal Penelitian Administrasi Publik, 2(2), 343-354. 